\title{
A Substance Use Prevention Framework: Considering the Social Context for African American Girls
}

\author{
Barbara J. Guthrie, Ph.D., R.N., and \\ Lisa Kane Low, M.S., R.N., C.N.M.
}

\begin{abstract}
Shifting patterns of substance use (that is, early initiation, increased marijuana use, narrowing differences in gender use) and the disproportionate socioeconomic obstacles that are related to substance use among ethnically diverse adolescent females create the need to develop ethnic and gender-specific substance use prevention frameworks. This article describes and applies a substance use prevention framework to African American females. Gender socialization and self-efficacy are presented as key concepts, along with the assertion that every substance use prevention framework should examine the influences of specific societal factors (such as racism, sexism, classism, and ageism) on substance use. Rationale and guidelines for designing ethnically sensitive and gender-specific research projects and intervention programs regarding substance use prevention are offered. Public health nurses (PHNs) are uniquely positioned to use this framework in their work with African American adolescent girls, specifically, and in general with other ethnically diverse groups.
\end{abstract}

Key words: substance use, African American adolescent females, risk prevention, gender-specific prevention program, substance use and social context, adolescent health, substance use prevention.

Barbara J. Guthrie is an Assistant Professor/Research Scientist, and Lisa Kane Low is a Doctoral Candidate, University of Michigan, School of Nursing, Ann Arbor, Michigan.

Address correspondence to Barbara J. Guthrie, University of Michigan, School of Nursing, 400 N. Ingalls, Ann Arbor, MI 48109-0482. E-mail: bguthrie@umich.edu

\section{INTRODUCTION}

Census figures indicate a rapid growth in the U.S. adolescent population, which currently numbers over 65 million and is projected to increase $15 \%$ by the year 2000 . By the year 2030, nearly $18 \%$ of adolescents will be of African American descent (U.S. Bureau of the Census, 1992). Additionally, the once noted gap in marijuana use between African Americans and European Americans has narrowed. The 1997 Monitoring the Future (MTF) Report: Drug Use Among American Teens Shows Some Signs of Leveling After a Long Rise (Johnston, O’Malley, \& Bachman, 1997) and the National Household Survey on Drug Abuse (NHSDA) (U.S. Department of Health and Human Services [USDHHS], 1997) indicated that the annual prevalence rate of marijuana between 1996 and 1997 was higher for African Americans than for European Americans. Annual surveys by Johnston et al. $(1997,1998)$ suggest that over the past 20 years, overall substance use rates have been higher for males than for females, except in the case of cigarette smoking. There is some indication, however, that these gender differences may be an artifact of timing. For example, while male substance use rose between 1975 and 1978, female use only peaked in 1981. Since 1993, however, gender substance use patterns have shifted notably, indicating previous differences between males' and females' (specifically 8th and 10th graders) substance use are narrowing (Jenson, Howard, \& Jaffee, 1995).

Negative societal influences, coupled with a scarcity of ethnic and gender-specific substance use prevention programs, do not adequately prepare African American adolescent females to refuse alcohol, cigarettes, and other substances. Although many African American girls adjust 
well to normal developmental transitions such as changing schools, cognitive and physical changes, and relational changes, many still face the challenge of poverty, unsafe schools, and unstable families. This leaves them susceptible to alcohol, tobacco, or other substance use. Thus, both gender and ethnicity can no longer be conceptualized as shields from substance use. These trends strongly point to the need to develop innovative substance use prevention frameworks that are ethnically sensitive and gender specific for adolescents. This is especially important in light of the fact that health promoting and health compromising behavioral patterns are often established during adolescence.

This article posits a specific conceptual framework to guide substance use prevention with African American adolescent females. More specifically, the framework's key constructs include ethnicity, gender socialization, and selfefficacy. A review of these constructs is provided along with supporting documentation and strategies for future nursing research and practice based on this framework.

\section{BACKGROUND}

Common and distinct determinants of substance use among adolescent females are better understood by reviewing trends and limitations of selected national, regional, and local studies. Currently, two major surveys-NHSDA (USDHHS, 1997, 1998a) and the MTF (Johnston et al., 1997, 1998) — provide national data on youth substance use rates and trends.

Changing trends related to the perception of risk and substance availability among 12 to 17-year-olds are highlighted by findings from NHSDA (USDHHS, 1996), which show that half of these youth report perceived risk in using marijuana occasionally and trying cocaine, PCP, or heroin once or twice. The same $50 \%$ also report greater risk of harm in consuming five or more drinks at least once a week, or in smoking one or more packs of cigarettes per day. More than $50 \%$ of the population report that marijuana is easily accessible, while $39 \%$ report that cocaine is easy to acquire, and $26 \%$ report easy access to heroin. The percentage of the population who reports being approached in the past month by someone selling drugs is $8.7 \%$. This percentage, however, ranges from $6.2 \%$ from surveys conducted in suburban and rural areas to $10.2 \%$ within inner city areas. An alarming 37\% of African Americans and $21.1 \%$ of Latinos observe drugs being sold in their neighborhoods, in contrast to $6.7 \%$ of European Americans. These rates have remained steady since 1990 .

The 1997 MTF (Johnston et al., 1997, 1998) data suggest no change from the prior survey in the reported availability of marijuana at any grade level. This study did note, however, increased disapproval rates among 8th graders regarding marijuana use. According to MTF data, 8th and 10th graders' use of crack, marijuana, and cocaine leveled off in 1997, while the increased acceleration of substance use was slower for 12th graders compared to years past. While overall lifetime rates of African American girls who have used illicit substances $(27 \%)$ are lower than their European American (32.6\%) counterparts, reported use of marijuana, crack, and heroin in the past year and past month are higher for African American girls (USDHHS, 1997, 1998b). This suggests a potential toward a future narrowing of differences.

The main trends that can be extrapolated from the NHSDA and MTF data suggest the following: youth in both surveys report less perceived risk associated with drug use and a more receptive attitude toward drugs than in past years. Both surveys found that drugs are more easily accessible to young people, particularly African Americans and Latinos, and reported narrowing differences in substance use between genders and ethnic groups (USDHHS, 1998b). The early initiation and increased receptiveness among youth ages 12 to 17 years should signal to researchers and practitioners that existing intervention strategies are not as effective with ethnically diverse age groups. The national findings, however, do not report the common and distinct determinants of substance use for adolescent females of color, which can be considered a significant limitation of these surveys.

To approach the study of ethnic differences in adolescent substance use rates, researchers should begin examining regional and local studies in tandem with national reports. Although national prevalence rates provide some insight into rates of use for African American adolescents, the sample pool for this group tends to be based on urban, lower-income areas, while European American subjects are generally drawn from middle to upper-middle class suburban settings. Thus, the differences between groups are potentially amplified on the basis of class and geographic environment. Furthermore, national prevalence rates do not directly inform researchers about the prevalence and intensity of drug use or the availability of drugs within poor or working-class ethnically diverse neighborhoods. The high quantity of drug-related problems generally associated with ethnically diverse adolescent drug use may be the result of teens' increased access to drugs in specific urban environments, as noted by accessibility data from $M T F$ and a regional study by $\mathrm{Li}$ and colleagues ( $\mathrm{Li}$, Feigelman, Stanton, Galbraith, \& Huang, 1998).

Regional and local studies provide researchers with clear and specific data on the ways environmental factors influence ethnically diverse adolescents' substance use in specific geographic regions. Results often contrast dramatically. For example, Welte and Barnes (1987) in New York found the highest rate of cigarette use to be among European American adolescents while Maddahian, Newcomb, 
and Bentler (1988) in California found higher rates for African American adolescents. Clearly, new models of prevention will have to account for regional and indigenous diversity as well.

Differences in substance use patterns between various U.S. ethnic groups have been well documented. Studies have found that African Americans under the age of 35 consistently report lower rates of any substance use than European Americans; the most prominent differences appear during early adulthood (ages 18 to 26 years). Additionally, most research documents African American adolescent females as less likely to initiate early use of alcohol and cigarette smoking than their Latina or Asian American peers (Centers for Disease Control [CDC], 1993; Kim, Coletti, Williams, \& Hepler, 1995). The Youth Risk Behavior Survey (CDC, 1998), however, noted that although African American adolescents currently smoke fewer cigarettes than their European American peers, their percentage of use doubled between 1991 and 1997, from $12.6 \%$ to $22.7 \%$.

African Americans younger than 35 years old are less likely to report any lifetime experiences with cocaine than their European Americans peers. Among those 35 years and older, however, 51.5\% more African Americans than European Americans report such experiences. This trend, however, seems to be changing. Specifically, the disparity in prevalence rates between African Americans and European Americans is disappearing and the rate of substance use among older African Americans is spreading to the younger cohort-particularly marijuana, cocaine, crack-cocaine, and heroin use among 12 to 17 -year-olds (USDHHS, 1998b).

\section{African American Adolescent Females' Substance Use}

Overall, more published research documents substance use patterns among African American and Latino youth than Native American and Asian American youth (USDHHS, 1998b). A great deal, however, still remains unknown about factors related to the specific determinants of African American adolescent female substance use. Most research findings indicate that African American adolescent females are less likely to initiate early alcohol and cigarette use than Latina and Asian American adolescent females (CDC, 1993; Kim et al., 1995). In a study of adolescent girls in the Midwest, however, Guthrie (1990) found that social context strongly influences alcohol and tobacco use among African American adolescents, with African American girls more likely to drink and smoke in situations such as teen parties and while dating older boys. Other studies found higher cocaine-related emergency room admissions for African American girls and that boyfriends played a key role in the substance use initiation process (Lowry, Hotzman, Truman, \& Kann, 1994).
For African American females, there is a greater increase in substance initiation and use with the transition from middle to high school when they are compared to their male peers (Brunswick, 1999; Henderson, 1997; Warheit, Vega, Khoury, \& Gil, 1996). Although African American females initiate drinking at an older age than their European American peers, they experience disproportionately higher consequences of heavy drinking and alcohol-related problems including unprotected sex, truancy, and use of illicit drugs (Castro, Maddahian, Newcomb, \& Bentler, 1987; USDHHS, 1998b). Furthermore, African American adolescent females are more likely than European American females to proceed from marijuana use into cocaine, crackcocaine, and heroin use, often accompanied by heavy alcohol intake (Li et al., 1998).

While changing gender roles are shifting girls into more powerful positions, firmly entrenched social and developmental differences between males and females still result in different pathways to substance use and abuse. Therefore, it is imperative to develop both gender-specific and ethnically sensitive substance-related frameworks to guide research and practice with diverse adolescents and in particular, African American adolescent females.

The social locations of class, gender, ethnicity, and "isms" place African American adolescent females in a socially marginalized position that facilitates neither a public nor a private awareness of their experiences, strengths, and knowledge. In order to begin to reverse the upward trend of alcohol, cigarette, and other substance use among these adolescent females, new and expansive genderspecific frameworks must be developed.

\section{PROPOSED GENDER-SPECIFIC AND ETHNIC- SENSITIVE SUBSTANCE USE PREVENTION FRAMEWORK}

In order to ensure that data generated from substancerelated research can be used to guide the development of effective and relevant substance prevention programs, the conceptual framework should examine how the broad societal influences (that is, racism, sexism, classism) intersect to have a direct or indirect impact on the determinants of substance use (that is, gender socialization and self-efficacy) for diverse ethnic adolescents and in particular for African American adolescent females.

\section{Key Constructs}

To fully understand why the broad societal influences should become central constructs within any substance prevention framework, it is necessary to understand the key terms. The following section further details the constructs of "isms" - ethnicity, social class, ageism, environ- 
ment, gender, gender-specific development, gender socialization, and self-efficacy.

\section{"Isms"}

An ism is an oppressive system of relationships that is justified by ideology in which one group benefits from dominating another, and defines itself through this domination (Krieger, Rowley, Herman, \& Avery, 1993; Williams \& Collins, 1995). The definition this framework uses for "ism"-as in sexism, racism, and classism-has been drawn from several authors. Examples of this are the subordination of women by men, minority cultures by the majority culture, and the poor by the rich. It involves harmful and degrading beliefs that can be either overt or subtle. "Isms" are held and enacted by institutions and individuals that are linked by their common membership to a predefined social group. Translated into action, "isms" often create inequalities in living conditions, health, resources, and opportunities between members of privileged and oppressed groups (Krieger et al., 1993; Williams \& Collins, 1995).

\section{Ethnicity}

The terms ethnicity and race are frequently used interchangeably. According to Hirschfeld (1996) and Williams (1991), race is an imaginary, socially designated construct with no biological basis. Classifying race as a biological trait infers that genetic differences cause observed racial differences. This perspective plays a pivotal role in predicting political power differentials and access to resources. Hence, race does not explain disadvantages so much as it explains away disadvantage by distorting perceptions of other relationships (Winant, 1994). The use of race further legitimizes and misrepresents the way power is wielded and opportunity is apportioned. Hirschfeld (1996) further posited that race is a closed system of practice and thought, while "racial thinking" (p. 2) serves as a rationalization for inequitable distribution of power and resources associated with the arbitrary status of race. If researchers do not begin to clarify their conceptualization of race in research questions and interpretations, the generated findings will continue to obscure determinants of observed variation in research.

Self-defining ethnic categories may be an alternative to using racial categories. Although ethnic identity is a social construct, unlike the category of race it is based on nationality and allows individual self-identification with a specific group. Ethnic identity is a manifestation of interactions with a specific group as well as the transmission and assimilation of values, beliefs, and attitudes of the group. Ethnic identity entails a sense of belonging to a specific group as well as the thoughts, feelings, and behaviors that are a result of this perceived affiliation. Inherent in one's ethnic identity are such things as ethnic awareness, ethnic selfidentification, values, and choice of reference group (Rotheram \& Phinney, 1987). As such, ethnic identity is a multidimensional construct (Phinney, 1996).

The most common ethnic social identities are as follows: identification with the mainstream, strong ethnic identification, and bicultural identification. To possess strong ethnic identification is to align oneself with a country or family of origin's ethnicity and to retain these traditional values, norms, and behavioral patterns. Stonequist (1964) hypothesized that biculturalism reflects the stress of being caught between two cultures. Others feel biculturalism reflects a cognitive and behavioral flexibility, an adaptive mechanism that could protect or benefit African American adolescent females (Ramirez, Castaneda, \& Herold, 1974). Adolescents of color who report a strong ethnic identity accompanied by a positive mainstream orientation are likely to have higher self-esteem and lower substance use than those who only self-identify as mainstream (McLoyd \& Steinberg, 1998; Rotheram-Borus, Dopkins, Sabate, \& Lightfoot, 1996).

An additional consideration noted by several researchers (Phinney, 1996; Walters \& Simoni, 1993) is a gender difference in the process of identifying and committing to one's ethnic identity, with African American females accomplishing traditional developmental tasks in nontraditional timelines. Additionally, recent research findings provide evidence of the importance of social influences like sexism and classism on the development of adolescent ethnic identity formation (Schonen et al., 1997; Ward, 1996).

\section{Social Class}

Social class is a construct integral to any substance use theoretical framework. There is no current consensus on the exact definition of class and how it should be measured. The American Heritage Dictionary (1985) defined class as a social stratum whose members share similar economic, political, and cultural characteristics. In research and literature, the term socioeconomic status (SES) is widely used as a proxy for social class. The generally preferred term "SES" reflects the Weberian notion that income, education, occupation, and property ownership stratify people. SES clarifies the complexities of social and historical processes, and predicts variations within and between social groups on the basis of living conditions, life chances, type of skill, material resources, and relative power and privilege. SES is also a reliable marker for measuring health and health status. Because SES is conceptualized and measured in so many different ways, however, its effectiveness has been called into question (Fee \& Krieger, 1993).

Fee and Krieger (1993) suggested that SES should be defined and measured at the levels of the individual, the household, and the neighborhood. At the individual level, 
occupation might be measured; at the household level, standard of living (times moved in last year or home ownership) and cultural patterns (number of people living within one apartment or house) could be examined; and at the neighborhood level, one could review neighborhoodrelated conditions (the availability of drugs, the crime rate, and the number of vacant homes). This multileveled measurement is posited to more accurately reflect the total impact of SES in contrast to a single indicator.

\section{Ageism}

Ageism is discrimination based on an individual's chronological age. While awareness of the impact of ageism has been heightened in reference to health promotion within elderly populations, it has rarely been considered in reference to adolescents. Ageism perpetuates a homogenous approach to all adolescents rather than recognizing the diversity within the adolescent population that extends beyond chronological age. In particular, the impact of ageism on substance use prevention programs for adolescents has not been explicated. The assumption is that appropriate models will be developmentally driven and thus age appropriate. Within this framework, ageism becomes significant in reference to the socially constructed developmental expectations and resultant sanctions those adolescents' experience when they do not conform to them. In particular, for African American adolescent females, it has been suggested that while the age may be the same for a group, the developmental tasks that they are attending to are different when compared to their European American peers (Robinson \& Ward, 1991). Considering the impact of ageism allows for broader consideration of the roles that an individual may play within their family and community that are not necessarily consistent with a linear developmental model or with a chronological age. Some common examples are caretaker of parents or other siblings, being employed, living without adult supervision, dropping out of school, and pregnancy.

For African American adolescent girls, consideration of this construct promotes the need to understand such global statistics as later initiation of substance use when compared to their European American peers verses the experience at the community or individual level. Age, for African American adolescent females, cannot be viewed as protective when other statistics indicate that for various cohorts the use of certain substances has actually increased and the difference between age at initiation has continued to approach that of European Americans (USDHHS, 1998b).

\section{Environment}

According to Levine and Perkins' (1987) study, several environmental factors influence drug initiation and maintenance. These factors include individual, family, peer, community, and societal dimensions. Petraitis, Flay, and Miller,
(1995) posited that each of these dimensions could be ranked according to its influence on substance use. At the individual level, psychobehavioral variables are considered the most important in the initiation and maintenance of substance use (Newcomb, 1995). Several studies link the following psychobehavioral variables with substance use: low conventionality (Jessor, Donovan, \& Costa, 1991; Newcomb, Maddahian, \& Bentler, 1986), low educational achievement and aspirations (Gottfredson, 1988; Johnston, O'Malley, \& Bachman, 1989), emotional distress (Newcomb \& Harlow, 1986; Shedler \& Block, 1990), childhood sexual abuse (Harrison, Hoffmann, \& Edwall, 1989; Singer \& Petchers, 1989), stressful life-events (Barrera, Li, \& Chassin, 1993), low self-esteem (Dielman, Campanelli, Shope, \& Butchart, 1987), and health beliefs and coping styles (Chassin \& Barrera, 1993).

Family and peer groups are the next dimensions of influence, followed by community and society. At the family and peer group level, findings from various studies suggest a positive relationship between adolescent substance use and family related factors (Brook, Brook, Gordon, Whiteman, \& Cohen, 1990; Brook, Nomura, \& Cohen, 1989), parental substance use (Brook, Whiteman, Gordon, \& Brook, 1985; Stice, Barrera, \& Chassin, 1993), and peer influences (Johnston, O'Malley, \& Bachman, 1989; Welte \& Barnes, 1987). At community and societal levels, availability of substances (Gottfredson, 1988; Rabow \& Watts, 1989), substance use legislation (Holder \& Blose, 1987; Joksch, 1988), poverty (Bursick \& Webb, 1982; Murray, Richards, Luepker, \& Pallonen, 1987), and neighborhood disintegration (Dembo, Schmeidler, Burgos, \& Taylor, 1985; Fagan, 1988) have been associated with substance use. According to Link and Phelan (1995), while factors at these levels help in evaluating the likelihood of adolescent initiation, continuation, and progression of substance use, the focus remains on individual traits and behaviors, and less on the reciprocal nature between the individual and environment. Further, these factors do little to heighten understanding of the specific environmental conditions ("isms") that increase the likelihood that African American adolescent females will use or abuse substances. Thus consideration of the interactional and reciprocal relationship between the individual and the environment is essential to this proposed framework.

\section{Gender}

The word gender comes from the Latin word "genus," which means any group of similar things, kinds, or classes. It also is defined as the possession of common structural characteristics distinct from those of any other group (American Heritage Dictionary, 1985). Unfortunately, the term gender is erroneously interchanged with the term sex to describe the origin of male and female characteristics. 
In actuality, sex refers to biological differences between males and females, whereas gender refers to socially constructed differences influenced by ethnicity, culture, and environment (for example, masculinity and femininity) (Udry, 1988).

Most of the available research findings comparing sex differences are unclear or inconsistent, particularly in the case of social behaviors such as the initiation of substance use (Henley, 1985; Spence, Pred, \& Helmreich, 1989). Moreover, when differences are found, they generally account for less than $5 \%$ of the variation being examined (Deaux, 1995). Viewing gender as a social construct within a substance use framework redefines gender from a variable or a property of an individual to a principle of social organization that is influenced by racism and situated within ethnicity, environment, and class. For example, lowincome African American adolescent females who face the threat of discrimination, racism, and violence in their daily lives may experience feelings of loneliness, alienation, helplessness, powerlessness, hopelessness, and low selfesteem. All of these are frequently associated with alcohol, tobacco, and other substance use (Krohn \& Thornberry, 1999).

\section{Gender-Specific Development}

Researchers are only beginning to understand the unique ways in which the developmental changes of adolescence affect girls; however, recent studies have paid closer attention to the female adolescent experience. The result is a gender-specific approach to the study of adolescent development, health, and well-being.

From a research standpoint, it is important to identify gender differentiation in developmental issues to reveal the distinct ways in which girls and boys view the world, whether these are considered to be the result of biological or social construction. For example, Gilligan, Lyons, and Hanmer (1990) from the Project of Women and the Development of Girls argued that moral reasoning is genderspecific. Gilligan et al. (1990) asserted that for men, morality revolves around issues of fairness and justice, whereas for women, a concern for the well-being of others is paramount. Building on this, theorists point out that morality based on communal concerns stems from all awareness of the " . . . extent to which one's sense of self is comprised of relations with others" (Cross \& Markus, 1991, p. 597). In their work on the therapeutic implications of a relational perspective, Jean Baker-Miller and colleagues at the Wellesley College Stone Center suggested that a sense of connection to others was the hallmark of healthy identity development for girls (Jordon, Kaplan, Miller, Stiver, \& Surrey, 1991). Consequently, one of the major developmental tasks that girls encounter is learning how to participate in mutual relationships in which they feel both active and effective.
Acknowledging diversity minimizes the potential for describing girls in biased and stereotypical ways. For example, negative stereotypes such as poor school performance, high dropout rates, teen pregnancy, and delinquent-related behaviors have long been associated with African American adolescent females. Racial, ethnic, economic, and physical differences are just a few of the factors that have an impact on a girl's sense of self and her ability to interact with others in equitable, productive, and healthier ways (Ward, 1996).

\section{Gender Socialization}

Gender socialization is the process of becoming aware of the importance of acquiring specific cultural norms, attributes, and characteristics associated with genderrelated behaviors (Mishler, 1986). This definition clarifies the historical, sociocultural, and structural factors that affect gender identity. It treats gender as a social relationship, influenced by and negotiated along changing axes of ethnicity, age, environment, and class. This gendering process teaches males and females specific cultural norms of masculinity and femininity. A female learns not just how to be a woman, but how to be a certain kind of woman according to her ethnicity and social class. Through this process, a young female becomes increasingly aware of the fact that within her environment she is rewarded for certain behaviors and punished for others.

The introduction of gender socialization as a construct influenced by environment, class, age, and ethnicity challenges single-gender linear models of human development, such as those originated by Erikson (1950) and Piaget (1955). Working from the single viewpoint of Caucasian male development, these theorists postulated that growth through a series of defined stages represents movement through tasks towards autonomy and a more complex understanding of self.

Feminist scholars offer alternative theories of development for females. Miller (1976, 1986) proposed that a female's sense of self was built around her ability to enter into and maintain relationships. The early works of Chodorow (1978) suggest differentiating stages of male and female gender development based on the fact that women are primarily responsible for early child care. As a result, Chodorow believes females are more likely to have experiences similar to their mothers, leading to a fusion of their life experiences with their gender identity development. Conversely, male children may envision themselves as different from their mothers and find separation as the key to developing a masculine identity. Schaef (1989) viewed the female developmental process from a sociological perspective-a female's environment, culture, and ways of dealing with the world are different from those of European American males. She posited that environmental systems such as families, schools, and communities create these 
socializing realities. For females, these environmental systems continuously reinforce the value of intimacy and responsibility, while teaching males to value separation and differentiation. Rather than establishing gender socialization as a linear, incremental movement toward more independence and autonomy, these scholars emphasize a cyclical, continuous process of self-definition within the context of establishing and maintaining important relationships.

Because gender and ethnicity cannot be wholly separated, researchers must also study the ethnic variations in expected gender roles for females (Winant, 1994). Scientists researching adolescent females of color must understand the broad universal context of adolescence as well as the more specific context of ethnicity. Inherent in the contextualization are ethnic differences and traditions, cultural expectations and stereotypes, and negative portrayals of ethnic females in American society and popular culture. These all indirectly or directly influence an African American adolescent female's perception of herself as well as how she is perceived by others. Her perception of herself can then serve as an antecedent to the avoidance of or use of substances.

\section{Self-Efficacy}

Self-efficacy is an individual's belief that s/he can exert control over his/her motivation (Bandura, 1992). A person with a strong sense of self-efficacy believes s/he can perform a specific behavior in the context of a social situation, with the appropriate support for that behavior (Bandura, 1994; Schifter \& Ajzen, 1985). Self-efficacy includes knowing how much effort to expend and how long to persist in the face of obstacles (Bandura, 1994). It can be a critical mediator of personal action and behavior change (Bandura, 1994).

For an adolescent female, self-efficacy creates an essential bridge between her thoughts and her actionsespecially as these relate to health-promoting skills and the ability to actualize these skills in vulnerable situations (that is, refusing substances from her boyfriend). Effective substance prevention programs must include experiential activities (such as "what if" scenarios) related to enhancing an adolescent female's perception of domain and behavior-specific self-efficacy.

\section{SUMMARY}

These constructs have been synthesized into a substance use prevention framework for African American adolescent females. This proposed framework considers how broad societal factors like the "isms," ethnicity, social class, and environment intersect and influence gender socialization. This framework posits that gender socialization is an essential pathway to self-efficacy, substance use, or nonuse behaviors. It examines how the perception of gender socialization directly or indirectly affects adolescent females and specifically ethnically diverse adolescent females. The consequences of gender socialization then affect an adolescent female's perceptions of global and domainspecific self-efficacy, and the proposed framework explores how these perceptions influence an adolescent female's likelihood of engaging in substance use or non use (Guthrie, Caldwell, \& Hunter, 1997) (see Fig. 1).

\section{IMPLICATION FOR PRACTICE AND FUTURE RESEARCH}

\section{Practice}

Public health nurses (PHNs) are uniquely positioned to design and implement substance use assessment, prevention, and intervention strategies by virtue of their focus on multiple levels of targeted interventions, as well as their neighborhood and community health perspective. The substance use prevention framework approaches this process from a strength-based approach that acknowledges both the individual and the community s/he lives in as interventions are designed. Furthermore, it can be applied at all levels of intervention: assessment, prevention, intervention, and surveillance regarding substance initiation and use. This avoids the risks of generalizing and stereotyping that has been pervasive in previous substance use programs.

The following strategies are offered to facilitate the design of relevant and effective prevention programs for diverse ethnic adolescent females. The most important guideline is the participation of adolescents who mirror the intended population in the creation and evaluation of the program. When this is not feasible, to increase the relevance and effectiveness of the program, it should be

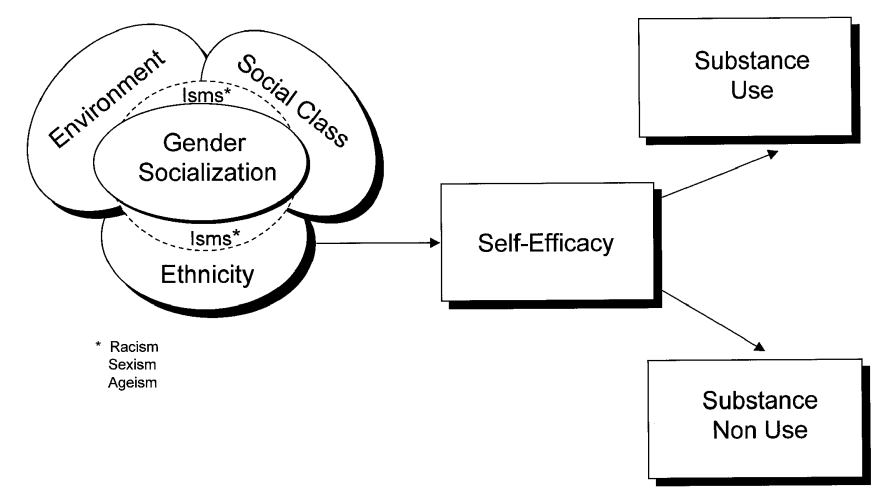

Figure 1. Adapted from Guthrie, B. J., Caldwell, C. H., \& Hunter, A. G. (1997). Minority adolescent female health strategies for the next millennium. In D. K. Wilson, J. R. Rodrique, \& W. C. Taylor (Eds.), Health-promoting and health compromising behaviors among minority adolescents. Washington, DC: American Psychological Association. 
critiqued and refined in concert with the intended participants. Additionally, intervention programs should be:

- Offered at times and places where the adolescents are known to congregate (that is, recreational centers, churches, schools, and neighborhood centers).

- Theory-based in order to provide sounder, more effective evaluation of the program's overall and specific efficacy.

- Experiential in nature (that is, interactive dialogue, "what if" role-playing scenarios, videos, and interactive computer games).

- Led by older peers who mirror the intended audience. This helps to build the participants' confidence and capabilities.

- At a level of discourse that is familiar to and understood by the intended group.

- Aware of the impact of broad societal factors such as racism, classism, and sexism on the participants' desire and ability to actualize or refine their relational skills.

- Encouraging participants' exploration and understanding of how their ethnic backgrounds influence their perceptions and expectations related to being female (that is, heritage exercise such as a Women's Tree [similar to a family tree in that participants are asked to identify all the women in their family and what they have learned from them]).

- Supportive of participants' strengths by way of selfaffirming and self-valuing activities (that is, transitional rituals, celebration programs).

- Community-based. This refers to the importance of seeking active collaboration of various organizations, groups, and families prior to the design and implementation of a program. It is important to note that adolescents do not define or create unhealthy communities; their behavior, however, may be symptomatic of an unhealthy community. Thus, it is important for the intervention to be integrally located within the adolescent's community.

Finally, in keeping with a relational perspective, Amaro (1995) suggested that prevention programs, as well as other health education programs for adolescent girls, can be more effective if health care providers in general and PHNs in particular, place a greater emphasis on the degree to which adolescent girls' participation in health-compromising behaviors (that is, drinking, smoking, sexual intercourse) take place in the context of romantic or sexual relationships. PHNs, who are involved with multiple members of a family as well as within the community, have the opportunity to attend to these contextual aspects in ways that are both direct and indirect as they address the issue of substance use for adolescent females in general and African American females specifically.

\section{Future Research}

Scholars working in the adolescent substance use research and prevention area need to pose several questions in order to ensure that prevention and research designs are genderspecific, ethnically relevant, and age or developmentally appropriate. For example, when considering race and ethnicity, the following questions arise. Are race and ethnicity viewed as biological constructs or social constructs? Are these two terms interchangeable? Are race and ethnicity conceptualized within the proposed framework? Are they independent variables? The answers to these questions will help frame the design, expected outcome, and the potential to advance scientific knowledge. For example, if race and ethnicity are viewed as separate, yet interdependent social constructs that are conceptualized within the framework, scientific knowledge related to race and ethnicity is expanded. Further, the way these two terms are conceptualized within the framework is important because this provides the basis from which to interpret the results. Derivations of these same questions need to be posed with each "ism" to the degree that they are explicated and conscious decisions regarding their conceptualization and inclusion or exclusion are made. The proposed framework attends to the social context, as well as to the individual factors, in a broader effort to develop prevention programs and tailor intervention strategies for African American adolescent females.

\section{CONCLUSION}

In spite of this significant evidence, researchers, academicians, and practitioners continue to debate the usefulness of gender-specific and ethnically sensitive frameworks. Dissension centers on whether or not the gender-specific and ethnically sensitive approaches are worth the financial expense of developing separate frameworks. Furthermore, these same researchers express caution that gender-specific could still be subject to the male dominant view that has been pervasive in previous framework proposals that are founded on traditional developmental theories. The need to develop a gender-specific, ethnically sensitive framework that guides substance use research and prevention programs for adolescent females has been substantiated by the following factors: shifting trends in substance use among adolescent females; decreasing disparity in prevalence rates between ethnic groups and between male and females-particularly adolescents between the ages of 12 and 17; and frequent and intense health-related consequences of substance use for adolescent femalesespecially for African American adolescent females. These factors warrant increased effort toward tailoring conceptual frameworks, research designs, and prevention programs in order to ensure that they are ethnically and gender sensitive. 
This article provides such a gender specific, ethnically sensitive framework for designing substance-related research and prevention programs. The proposed framework is broad enough so that the uniqueness of diverse ethnic adolescent female groups are acknowledged and addressed. In addition, viable strategies are offered as guidelines for designing future nursing research and practice prevention projects.

\section{ACKNOWLEDGMENTS}

I gratefully acknowledge the support of the National Institute on Drug Abuse (Grant K20-DA000233-01A1) and my colleagues in the National Women's Resource Center Technical Experts Groups.

\section{REFERENCES}

Amaro, H. (1995). Love, sex, and power: Considering women's realities in HIV prevention. American Psychology, 50, 437-447.

American heritage dictionary (2nd ed.). (1985). Boston, MA: Houghton Mifflin Company.

Bandura, A. (1992). Self-efficacy mechanism in psychological functioning. In R. Schwarzer (Ed.), Self-efficacy: Thought control of action. Washington, DC: Hemisphere.

Bandura, A. (1994). Social cognitive theory and exercise of control over HIV infection. In R. J. DiClemente \& J. L. Peterson (Eds.), Preventing AIDS: Theories and methods of behavioral interventions. New York: Plenum Press.

Barrera, M., Li, S. A., \& Chassin, L. (1993). Ethnic group differences in vulnerability to parental alcoholism and life stess: A study of Hispanic and non-Hispanic Caucasian adolescents. American Journal of Community Psychology, 21(1), 15-35.

Brook, J. S., Brook, D. W., Gordon, A. S., Whiteman, M., \& Cohen, P. (1990). The psychosocial etiology of adolescent drug use: A family interactional approach. Genetic, Social, and General Psychology Monographs, 116, 111-267.

Brook, J. S., Nomura, C., \& Cohen, P. (1989). A network of influences on adolescent drug involvement: Neighborhood, school, peer, and family. Genetic, Social, and General Psychology Monographs, 115, 125-145.

Brook, J. S., Whiteman, M., Gordon, A. S., \& Brook, D. W. (1985). Father's influence on his daughter's marijuana use viewed in a mother and peer context. Advances in Alcohol and Substance Abuse, 41, 165-190.

Brunswick, A. F. (1999). Structural strain: An ecological paradigm for studying African American drug use. Drugs and Society, 14, 5-19.

Bursick, R. J., \& Webb, J. (1982). Community change and patterns of delinquency. American Journal of Sociology, 88, 24-42.

Castro, F. G., Maddahian, E., Newcomb, M. D., \& Bentler, P. M. (1987). A multivariate model of the determinants of cigarette smoking among adolescents. Journal of Health and Social Behavior, 28, 273-289.

Centers for Disease Control (CDC). (1993). HIV/AIDS surveil- lance report (April). Atlantic, GA: Department of Health and Human Services.

Centers for Disease Control (CDC). (1998). Tobacco use among high school students-United States, 1997. Morbid and Mortality Weekly Report, 47, 229-233.

Chassin, L., \& Barrera, M. (1993). Substance use escalation and substance use restraint among adolescent children of alcoholics. Psychology of Addiction Behavior, 7, 3-20.

Chodorow, N. (1978). The reproduction of mothering. Berkeley: University of California Press.

Cross, S., \& Markus, H. (1991). Possible selves across the life span. Human Development, 34, 230-255.

Deaux, K. (1995). How basic can you be? The evolution of research on gender stereotypes. Journal of Social Issues, 51, 11-20.

Dembo, R., Schmeidler, J., Burgos, W., \& Taylor, R. (1985). Environment setting and early drug involvement among innercity junior high school youths. International Journal of Addiction, 20, 1239-1255.

Dielman, T. E., Campanelli, P. C., Shope, J. T., \& Butchart, A. J. (1987). Susceptibility to peer pressure, self-esteem, and health locus of control as correlates of adolescent substance abuse. Health Education Quarterly, 14(2), 207-221.

Erikson, E. (1950). Childhood and society. New York: W.W. Norton.

Fagan, J. (1988). The social organization of drug use and drug dealing among urban gangs. New York: John Jay College of Criminal Justice.

Fee, E., \& Krieger, N. (1993). Understanding AIDS: Historical interpretations and the limits of biomedical individualism. American Journal of Public Health, 83, 1477-1486.

Gilligan, C., Lyons, N., \& Hanmer, T. (1990). Making connections: The rational worlds of adolescent girls at Emma Willard School. Cambridge, MA: Harvard University Press.

Gottfredson, D. C. (1988). An evaluation of an organization development approach to reducing school disorder. Evaluation Review, 11, 739-763.

Guthrie, B. J. (1990). Race and gender differences in information regarding the meaning attached to adolescent's use and misuse of alcohol. Unpublished manuscript, University of Michigan, Ann Arbor.

Guthrie, B. J., Caldwell, C. H., \& Hunter, A. G. (1997). Minority adolescent female health strategies for the next millennium. In D. K. Wilson, J. R. Rodrique, \& W. C. Taylor (Eds.), Health-promoting and health-compromising behaviors among minority adolescents. Washington, DC: American Psychological Association.

Harrison, P. A., Hoffmann, N. G., \& Edwall, G. E. (1989). Sexual abuse correlates: Similarities between male and female adolescents in chemical dependency treatment. Journal of Adolescent Research, 4, 385-399.

Henderson, D. (1997). Intersecting race and gender in feminist theories or women's psychological development. Issues in Mental Health Nursing: Special Issue: Thoughtful Feminism in Mental Health Nursing, 18, 377-393.

Henley, N. M. (1985). Psychology and gender. Signs, 11, $101-119$. 
Hirschfeld, L. A. (1996). Race in the making: Cognition, culture, and the child's construction of human kinds. Cambridge, MA: The MIT Press.

Holder, H. D., \& Blose, J. O. (1987). Impact of changes in distilled spirits availability on apparent consumption: A times series analysis of liquor-by-the-drink. British Journal of Addiction, 82, 623-631.

Jenson, J. M., Howard, M. O., \& Jaffe, J. (1995). Treatment of adolescent substance abusers: Issues for practice and research. Social Work in Health Care, 21, 1-18.

Jessor, R., Donovan, J. E., \& Costa, F. M. (1991). Beyond adolescence: Problem behavior and young adult development. New York: Cambridge University Press.

Johnston, L. D., O’Malley, P. M., \& Bachman, J. G. (1989). Drug use, drinking, \& smoking: National survey results from high school, college, and young adult populations. 1975-1988. Rockville, MD: National Institute on Drug Abuse.

Johnston, L. D., O’Malley, P. M., \& Bachman, J. G. (1997, December 18). The 1997 monitoring the future (MTF) report: Drug use among American teens shows some signs of leveling after a long rise. News and Information Service. Ann Arbor, MI: University of Michigan.

Johnston, L. D., O’Malley, P. M., \& Bachman, J. G. (1998, December 18). Drug use by American young people begins to turn downward. News and Information Service. Ann Arbor, MI: University of Michigan.

Joksch, H. C. (1988). The impact of severe penalties on drinking and driving. Washington, DC: AAA Foundation for Traffic Safety.

Jordon, J. V., Kaplan, A. G., Miller, J. B., Stiver, I. R., \& Surrey, J. L. (1991). Women's growth in connection. New York: The Guilford Press.

Kim, S., Coletti, S. D., Williams, C., \& Hepler, N. A. (1995). Substance abuse prevention involving Asian/Pacific Islander American communities. In G. J. Botvin, S. Schinke, \& M. A. Orlandi (Eds.), Drug abuse prevention with multiethnic youth. Thousand Oaks, CA: Sage Publications.

Krieger, N., Rowley, D. L., Herman, A. A., \& Avery, B. (1993). Racism, sexism, and social class: Implications for studies of health, disease, and well being. American Journal of Preventive Medicine, 9, 82-122.

Krohn, M. D., \& Thornberry, T. P. (1999). Retention of minority populations in panel studies of drug use. Drugs and Society, 14, 185-207.

Levine, M., \& Perkins, D. V. (1987). Principles of community psychology: Perspectives and applications. New York: Oxford University Press.

Li, X., Feigelman, S., Stanton, B., Galbraith, J., \& Huang, W. (1998). Drug trafficking and drug use among urban AfricanAmerican adolescents. Journal of Adolescent Health, 23, 280-288.

Link, B. G., \& Phelan, J. (1995). Social conditions as fundamental causes of disease. Journal of Health and Social Behavior, (Extra Issue), 80-94.

Lowry, R., Hotzman, D., Truman, B. I., \& Kann, L. (1994). Substance use and HIV-related sexual behaviors among U.S. high school students: Are they related? American Journal of Public Health, 84, 1116-1120.

Maddahian, E., Newcomb, M. D., \& Bentler, P. M. (1988). Adolescent drug use and intention to use drugs: Concurrent and longitudinal analyses of four ethnic groups. Addictive Behavior, 23, 191-195.

McLoyd, V. C., \& Steinberg, L. (Eds.). (1998). Studying minority adolescents: Conceptual, methodological, and theoretical issues. Mahwah, NJ: Lawrence Erlbaum Associates, Publishers.

Miller, J. B. (1976). Toward a new psychology of women. Boston: Beacon Press.

Miller, J. B. (1986). Toward a new psychology of women (2nd ed.). Boston: Beacon Press.

Mishler, E. (1986). Research interviewing: Context and narrative. Cambridge, MA: Harvard University Press.

Murray, D. M., Richards, P. S., Luepker, R. V., \& Pallonen, U. (1987). The prevention of smoking in children: Two and threeyear follow-up comparisons of four prevention strategies. Journal of Behavioral Medicine, 10, 595-611.

Newcomb, M. D. (1995). Drug use etiology among ethnic minority adolescents: Risk and protective factors. In G. J. Botvin, S. Schinke, \& M. A. Orlandi (Eds.), Drug abuse prevention with multiethnic youth. Thousand Oaks, CA: Sage Publications.

Newcomb, M. D., \& Harlow, L. L. (1986). Life events and substance use among adolescents: Mediating effects of perceived loss of control and meaninglessness in life. Journal of Personality and Social Psychology, 51, 564-577.

Newcomb, M. D., Maddahian, E., \& Bentler, P. M. (1986). Risk factors for drug use among adolescents: Concurrent and longitudinal analyses. American Journal of Public Health, 76, 525-531.

Petraitis, J., Flay, B. R., \& Miller, T. Q. (1995). Reviewing theories of adolescent substance use: Organizing pieces in the puzzle. Psychological Bulletin, 117, 67-86.

Phinney, J. S. (1996). When we talk about American ethnic groups, what do we mean? American Psychologist, 51, 918-927.

Piaget, J. (1955). The language and thought of the child. New York: Meridian Books.

Rabow, J., \& Watts, R. K. (1989). The availability of alcohol and alcohol problems: Some theoretical explanations and empirical consequences. In S. Einstein (Ed.), Drug and alcohol use: Issues and factors. New York: Plenum Press.

Ramirez, M., Castaneda, A., \& Herold, P. L. (1974). The relationship of acculturation to cognitive style among Mexican Americans. Journal of Cross-Cultural Psychology, 5, 424-433.

Robinson, T., \& Ward, J. V. (1991). A belief in self far greater than anyone's disbelief. In C. Gilligan, A. Rogers, \& D. Tolman (Eds.), Cultivating resistance among African American female adolescents in women, girls, and psychotherapy. Binghamton, MA: Harrington Park Press.

Rotheram, M. J., \& Phinney, J. S. (1987). Definitions and perspectives in the study of children's ethnic socialization. In J. S. Phinney, \& M. J. Rotheram (Eds.), Children's ethnic socialization. Newbury Park, CA: Sage Publications. 
Rotheram-Borus, M. J., Dopkins, S., Sabate, N., \& Lightfoot, M. (1996). Personal and ethnic identity, values, and selfesteem among Black and Latino adolescent girls. In B. Leadbeater \& N. Way (Eds.), Urban girls. New York: University Press.

Schaef, A. W. (1989). Escape from intimacy: The pseudo-relationship addictions: Untangling the 'love' addictions: Sex, romance, relationships. New York: Harper \& Row.

Schifter, D. B., \& Ajzen, I. (1985). Intention, perceived control and weight loss: An application of the theory of planned behavior. Journal of Personality and Social Psychology, 49, 843-851.

Schonen, C., Davis, K., Collins, K. S., Greenberg, L., Des Roches, C., \& Abrams, M. (1997). The commonwealth fund survey of the health of adolescent girls (pp. 1-43). New York: The Commonwealth Fund on Women's Health.

Shedler, J., \& Block, J. (1990). Adolescent drug use and psychological health: A longitudinal inquiry. American Psychology, 45, 612-630.

Singer, M. I., \& Petchers, M. K. (1989). The relationship between sexual abuse and substance abuse among psychiatrically hospitalized adolescents. Child Abuse and Neglect, 13, 319-325.

Spence, J. T., Pred, R. S., \& Helmreich, R. L. (1989). Achievement strivings, scholastic aptitude, and academic performance: A follow-up to 'impatience versus achievement strivings in the Type A pattern.' Journal of Applied Psychology, 74, 176-178.

Stice, E., Barrera, M., \& Chassin, L. (1993). Relation of parental support and control to adolescents' externalizing symptomatology and substance use: A longitudinal examination of curvilinear effects. Journal of Abnormal Child Psychology, 21, 609-629.

Stonequist, E. V. (1964). The marginal man: A study in personality and culture conflict. In E. Burgess \& D. J. Bogue (Eds.), Contribution to urban sociology. Chicago: University of Chicago Press.

U.S. Bureau of the Census. (1992). Population projections of the United States, by age, sex, race, and Hispanic origin: 1992-2050. Current Populations Reports, Series P25-1092. Washington, DC: U.S. Government Printing Office.

U.S. Department of Health and Human Services (USDHHS). (1996, August). Preliminary estimates from the 1995 National Household Survey on Drug Abuse. Advance Report Number
18 (pp. 1-99). Rockville, MD: Substance Abuse and Mental Health Services Administration (SAMHSA), Office of Applied Studies.

U.S. Department of Health and Human Services (USDHHS). (1997, July). National Household Survey on Drug Abuse: Population estimates 1996, (pp. 1-123). Rockville, MD: Substance Abuse and Mental Health Services Administration (SAMHSA), Office of Applied Studies.

U.S. Department of Health and Human Services (USDHHS). (1998a). Preliminary estimates from the 1997 National Household Survey on Drug Abuse. Rockville, MD: Substance Abuse and Mental Health Services Administration (SAMHSA), Office of Applied Studies.

U.S. Department of Health and Human Services. (1998b). Prevalence of substance use among racial and ethnic subgroups in the United States 1991-1993. Rockville, MD: Substance Abuse and Mental Health Services Administration (SAMHSA), Office of Applied Studies.

Udry, R. (1988). Biological predispositions and social control in adolescent sexual behavior. American Sociology Review, 53, 709-722.

Walters, K. L., \& Simoni, J. M. (1993). Lesbian and gay male group identity attitudes and self-esteem: Implications for counseling. Journal of Counseling Psychology, 40, 94-99.

Ward, J. V. (1996). Raising resister: The role of truth telling in the psychological development of African-American girls. In B. J. R. Leadbeater, \& N. Way (Eds.), Urban girls resisting stereotypes, creating identities. New York: New York University Press.

Warheit, G. J., Vega, W. A., Khoury, E. L., \& Gill, A. A. (1996). A comparative analysis of cigarette, alcohol, and illicit drug use among an ethically diverse sample of Hispanic, African American, and non-Hispanic White adolescents. Journal of Drug Issues, 26, 901-922.

Welte, J. W., \& Barnes, G. M. (1987). Youthful smoking: Patterns and relationships to alcohol and other drug use. Journal of Adolescence, 10, 27-340.

Williams, D. R. (1991). Everyday racism scale. Unpublished instrument, University of Michigan.

Williams, D. R., \& Collins, C. (1995). U.S. socioeconomic and racial differences in health: Patterns and explanations. Annual Review of Sociology, 21, 349-386.

Winant, H. (1994). Racial conditions: Politics, theory, comparisons. Minneapolis: University of Minnesota Press. 